

\title{
Efeitos da rigidez nos impactos esclerométricos aplicados a vigas de madeira
}

\section{Fernanda D. Pereira*, Nádia S. da Veiga, Julio Soriano.}

\section{Resumo}

Os resultados do método de ensaio esclerométrico foram avaliados levando-se em conta a variação da rigidez de vigas de madeira. Para tanto, os impactos esclerométricos foram aplicados nas faces laterais de duas vigas fletidas a quatro pontos, tendo como variável o vão entre apoios. Concluiu-se que o aumento da rigidez, devido a redução do vão entre os apoios, fez diminuir de forma pouco significativa os valores dos impactos esclerométricos.

\section{Palavras-chave:}

Ensaios não destrutivos, esclerometria, flexão estática.

\section{Introdução}

As possíveis aplicações da técnica esclerométrica para caracterização e inspeção de peças de madeira (1) vêm sendo avaliadas pelo grupo do LabEND (FEAGRI). Tratase de uma técnica de Ensaios Não Destrutivos (END), que, para ser aplicada em campo, é necessário o conhecimento de fatores que possam afetar os resultados. A exemplo da rigidez, que por sua vez está relacionada com três parâmetros: o módulo de elasticidade, o momento de inércia e o vão livre da peça. Este trabalho teve por objetivo avaliar os efeitos da variação da rigidez de vigas nos resultados da esclerometria.

\section{Resultados e Discussão}

A resistência à flexão de um lote de três vigas de garapa (Apuleia leiocarpa) com seção transversal $50 \times 110 \mathrm{~mm}^{2}$ foi obtida por flexão estática a quatro pontos de uma das vigas, com vão livre igual a $3000 \mathrm{~mm}$. Com base no valor de $15 \%$ da resistência à flexão e nas equações da estática, foram calculadas as cargas relativas a três vãos entre apoios (Tabela 1), as quais foram aplicadas às duas outras vigas. Para cada uma das situações de carga e vão entre apoio, os impactos esclerométricos $(2,207 \mathrm{~J})$ foram aplicados com equipamento (Proceq) no segmento entre as cagas $(P / 2)$ e à meia altura das faces laterais das vigas. A análise estatística apresentou normalidade dos dados, através da análise de assimetria e curtose.

Figura 1. Esclerometria aplicada em viga de madeira sob flexão estática.

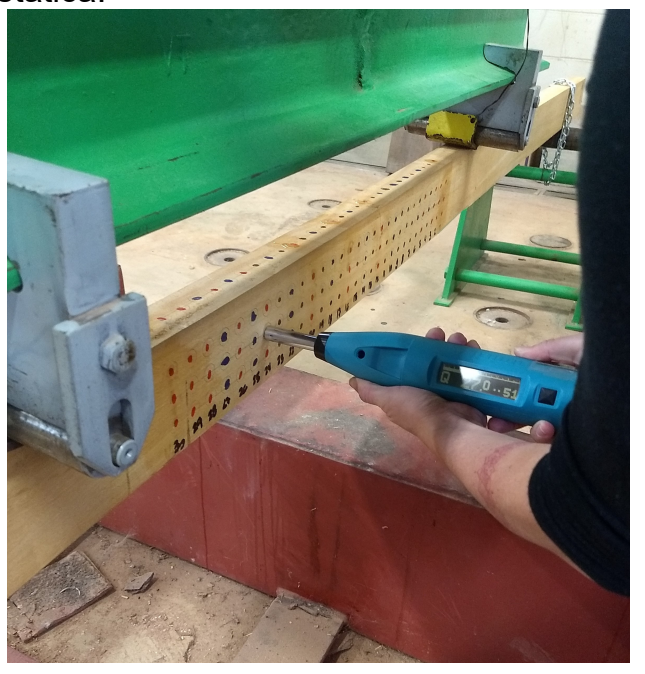

Para ambas as vigas, os índices esclerométricos foram numericamente reduzidos com a aproximação dos apoios (Tabela 1). Os agrupamentos analisados pelo método de Tukey (95\%) demonstraram que para a viga 2 os resultados da esclerometria não se diferenciaram estatisticamente com a redução do vão livre (e consequentemente, com a redução da rigidez). No caso da viga 1 , os resultados foram diferenciados para as situações extremas de vão livre, evidenciando que a energia restituída foi maior para o caso de maior vão.

Tabela 1. Índices esclerométricos e agrupamentos.

\begin{tabular}{cccccc}
\hline Viga & $\begin{array}{c}\mathbf{L}^{(\mathbf{a})} \\
(\mathbf{m m})\end{array}$ & $\begin{array}{c}\mathbf{P}^{(\mathbf{b})} \\
(\mathbf{N})\end{array}$ & $\mathbf{N}^{(\mathbf{c})}$ & $\begin{array}{c}\text { Índice } \\
\text { Esclerométrico }\end{array}$ & $\mathbf{G R}^{(\mathbf{d})}$ \\
\hline \multirow{3}{*}{1} & 3000 & 2240 & 24 & 26,8 & $\mathrm{~A}$ \\
& 2500 & 2687 & 18 & 24,4 & $\mathrm{~A} \mathrm{~B}$ \\
& 2000 & 3359 & 18 & 22,2 & $\mathrm{~B}$ \\
\hline \multirow{3}{*}{2} & 3000 & 2240 & 24 & 27,2 & $\mathrm{~A}$ \\
& 2500 & 2687 & 18 & 28,4 & $\mathrm{~A}$ \\
& 2000 & 3359 & 17 & 25,0 & $\mathrm{~A}$
\end{tabular}

(a) vão entre apoios; (b) carga de flexão; (c) número de impactos; (d) Agrupamento pelo Método Tukey a 95\% de confiabilidade.

Tendo em vista que ambas as vigas ensaiadas são de uma mesma espécie e que as condições estáticas foram idênticas, o comportamento distinto da análise estatística pode ser uma consequência da aptidão de absorção da energia aplicada, cabendo, portanto, a continuidade da pesquisa com peças de seções mais robustas e/ou aplicação de impactos com menor energia.

\section{Conclusões}

O aumento da rigidez decorrente da redução do vão entre apoio da viga resultou numa diminuição dos valores do índice esclerométrico. No entanto, essas diferenças devem ainda ser avaliadas em decorrência da inércia da seção transversal e intensidade da energia de impacto.

\section{Agradecimentos}

Conselho Nacional de Desenvolvimento Científico e Tecnológico (CNPq); Laboratório de Ensaios Não Destrutivos (LabEND - FEAGRI - UNICAMP).

1 Soriano, J.; Veiga, N.S.; Martins, I.Z. Wood density estimation using the sclerometric method. European Journal of Wood and Wood Products. v.73, p.753-758. 2015. 